Review Article

\title{
Molecular and Chromosomal Markers for Evolutionary Considerations in Torpediniformes (Chondrichthyes, Batoidea)
}

\author{
Lucia Rocco \\ Department of Life Sciences, Second University of Naples, via Vivaldi 43, 81100 Caserta, Italy \\ Correspondence should be addressed to Lucia Rocco; lucia.rocco@unina2.it
}

Received 23 May 2012; Accepted 22 June 2012

Academic Editors: M. Dmitrzak-Weglarz, G. Giovambattista, and H. Y. Lee

Copyright (C) 2013 Lucia Rocco. This is an open access article distributed under the Creative Commons Attribution License, which permits unrestricted use, distribution, and reproduction in any medium, provided the original work is properly cited.

\begin{abstract}
Due to their basal position in the vertebrate phylogenetic tree, the study on elasmobranch genetics and cytogenetics can provide remarkable information on the mechanisms underlying the evolution of all vertebrates. In recent years, different molecular approaches have been used to study the relationships between the different taxonomic groups of cartilaginous fish, among them are the physical mapping of specific nucleotide sequences on chromosomes. However, these are controversial, particularly in Torpediniformes in which the species have different karyological parameters. The purpose of this paper is to gather the molecular markers so far present in literature that were used to reconstruct the phylogenetic position of Torpediniformes with respect to the other Batoidea and to discriminate between the various chromosome pairs in the endemic species in the Mediterranean Sea, Torpedo torpedo, T. marmorata and T. nobiliana. The $5 \mathrm{~S}$ and $18 \mathrm{~S}$ ribosomal DNA, the HpaI and Alu SINE, the telomeric (TTAGGG) and the spermatogenesis-related SPATA 16, SPATA 18, and UTY sequences were particularly useful. These last genomic segments were also able to differentiate between the male and the female karyotypes. Moreover, the torpedoes showed a particular genomic organization, especially Torpedo torpedo, in which large quantities of highly repeated DNA and a characteristic distribution of heterochromatin, which is never centromeric, were observed.
\end{abstract}

\section{Introduction}

The Chondrichthyes (cartilaginous fish) are one of the three extant major clades of jawed vertebrates and comprise two sister groups, the elasmobranchs (rays, sharks, and skates) and the holocephalans (chimeras and ratfish). They occupy an important phylogenetic position as the sister group to all other jawed vertebrates and as one of the first lineages to diverge in vertebrate evolution [1]. Despite this, there have been relatively few studies about chondrichthyan genetics and cytogenetics.

Batoids are one of the biggest systematic groups that are included in elasmobranch fish [2]. Most batoids have a strongly depressed disc-like body derived from a rhinobatoid-like (as in rajids) or from a plathyrhinid-like (as in higher myliobatiformes) ancestor [3].

Many different views have been proposed on batoid interrelationships. In this paper, Batoidea higher classification by McEachran and Aschliman [3] and Nelson [2] has been given. According to these authors, Torpediniformes are to be considered as a sister group to the remaining batoids.

Torpediniformes, commonly named electric rays, are known for being capable of producing an electric discharge (up to 220 volts depending on species), used to stun prey and for defense. Electric rays are found from shallow coastal waters down to at least 1,000 metres depth.

Three species of Torpediniformes, belonging to family of Torpedinidae, are frequent in the Mediterranean Sea, the common torpedo Torpedo torpedo Linnaeus 1758, the marbled electric ray T. marmorata Risso 1810 and the black torpedo T. nobiliana Bonaparte 1835. The first is characterized by yellow-reddish stains on the back with five blue spots surrounded by a black halo; the second is the most common and exhibits a yellowish-brown body with dark spots. The third, purplish-brown back and whitish on the belly, which reaches one meter in length, is much less present. Although monophyly of the batoids (electric rays, sawfishes, guitarfishes, skates, and stingrays) is widely accepted and well 
corroborated, the interrelationships within batoids remain controversial. In particular, the most contentious issues concern the phylogenetic position of the Torpediniformes.

The aim of this paper was to report the already known molecular markers that were used to reconstruct the phylogenetic position of Torpediniformes with respect to the other Batoidea and to discriminate between the various chromosome pairs in the endemic species in the Mediterranean Sea. The $5 \mathrm{~S}$ and $18 \mathrm{~S}$ ribosomal DNA, the HpaI and Alu SINE, the telomeric (TTAGGG) ${ }_{n}$ and the spermatogenesis-related SPATA 16, SPATA 18, and UTY sequences have proved particularly useful. These last genomic markers were also able to differentiate between the male and the female karyotypes.

The molecular methods consisted of the analysis for ribosomal $16 \mathrm{~S}$ mtDNA and $18 \mathrm{~S}$ nuclear sequences. The cytogenetic assays collected the classic reconstruction of species karyotype and the fluorescence in situ hybridization (FISH) technique using the genomic fragments mentioned above.

\section{Phylogenetic Relationships and Karyological Properties}

The superorder taxonomy in cartilaginous fish is undergoing major revisions; currently there is no agreement as regards to the higher systematic level in these species. A large number of different interpretations exists in scientific literature based on morphological characters [3-11], on molecular studies [12$14]$, and on conventional cytogenetics $[14,15]$.

Many scientists consider that batoids are monophyletic, even if the time of their divergence from the other elasmobranch fish remains controversial. Several more recent morphological lines of evidence seem to support the derivation of batoids from sharks $[7,16]$, but immunological and molecular studies corroborate the hypothesis of batoids as separate from sharks $[13,17,18]$. However, molecular phylogenetic evidence published in the last few years has principally focused on relationships among the elasmobranch superorders. In fact, very few molecular studies addressing interrelationships within Batoidea have been published. One of them concerns only the phylogenetic relationships among the major lineages of myliobatoids, including one species for each of the four remaining batoid orders [19]. This paper represents the first attempt to introduce a species of Torpediniformes (used as an outgroup) in a phylogenetic reconstruction based on molecular markers (1528 bp of mtDNA: 12S, four tRNAs, fragments of ND1 and ND2).

The karyological approach could provide an informative tool to contribute to the corroboration of systematic relationships in Elasmobranchii, and particularly in Torpediniformes. In fact, many authors agree about an intimate correlation between the development of a new species and the simultaneous modification of its karyotype, confirming the close evolutionary links between chromosome number and morphology, speciation, and morphological diversification [20].

The Torpedinidae is the most investigated family of the order as concerns karyological morphology (5 species have
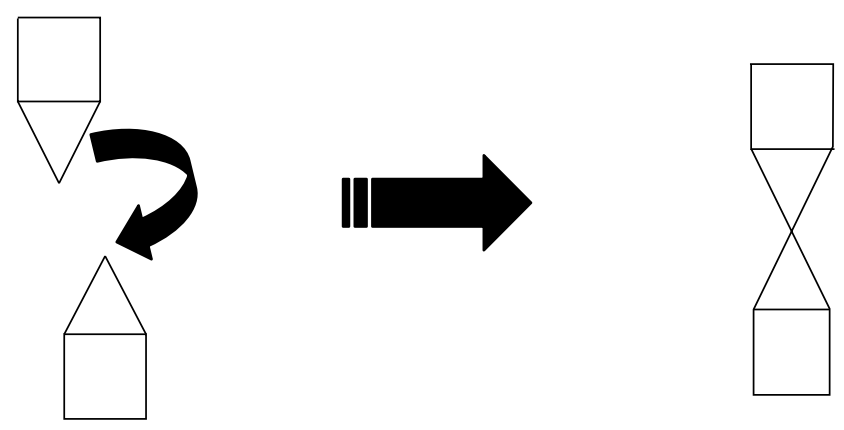

FIGURE 1: Schematic representation of karyologic evolution within Batoidea superorder that led to a progressive reduction of the diploid number. This chromosomal rearrangement took place from the less-evolved species to the most specialized through Robertsonian fusions, that is, centric fusions between two acrocentric elements to form a metacentric or a submetacentric one.

been examined to date). Only two species have been studied in the Narcinidae and Narkidae families, while no data are available for the Hypnidae family.

The species belonging to the order of the Torpediniforms exhibit different morphology in their karyotypes. In fact, considering the various species, it can be seen how their karyological parameters are different. They vary from $2 n=28$ and FN (fundamental number) $=56$ in Narcine brasiliensis to $2 n=86$ and $\mathrm{FN}=86$ in Torpedo marmorata and T. tokionis, with intermediate values in T. torpedo $(2 n=66, \mathrm{FN}=78)$ and Narke japonica $(2 n=54, \mathrm{FN}=82)$ (Table 1$)$. Moreover, their karyotypes do not show sex chromosomes [15].

The genome of many cartilaginous fish underwent a DNA increase during its evolutionary history followed by chromosomal rearrangements mainly in the form of fusions and translocations [15].

Especially within the superorder Batoidea karyologic evolution took place from the least evolved species to the most specialized. The progressive reduction of the diploid number, the increase of the number of chromosomes with two arms and the disappearance of microchromosomes occurred, probably as a consequence of polyploidy followed by diploidization and Robertsonian rearrangements (Figure 1) $[14,15,23,25-27]$.

This karyological pattern is clearly evident in the Torpedinidae family. In fact, in T. marmorata only elements with one arm are present, while in T. torpedo and T. nobiliana there is a reduction of the number of uniarmed elements and an increase in the number of biarmed chromosomes; it must also be noted that the FN is similar in all the Torpediniforms, except in Narcine.

In a previous work, the first assessment of relationships among different batoid species by using both ribosomal $16 \mathrm{~S}$ mtDNA and $18 \mathrm{~S}$ nuclear sequences was reported. These molecular data were further discussed with karyological evidence coming from the literature [14].

The phylogenetic results obtained by the analysis of the two separate gene sequences were similar to those coming from the combined data set. In general, $18 \mathrm{~S}$ sequences 
TABle 1: Karyological parameters for Torpediniformes species studied so far.

\begin{tabular}{llcccc}
\hline Species & $2 n$ & FN & $\mathrm{m} / \mathrm{sm}$ & t/st & References \\
\hline Narcine brasiliensis & 28 & 56 & 28 & 0 & Donahue [21] \\
Narke japonica & 54 & 82 & 28 & 54 & Ida et al. [22] \\
Torpedo torpedo & 66 & 78 & 12 & 54 & Stingo [23] \\
Torpedo nobiliana & 66 & 78 & 12 & 48 & Rocco (this work) \\
Torpedo californica & 82 & 86 & 0 & 86 & Ida et al. [22] \\
Torpedo marmorata & 86 & 86 & 0 & 86 & Stingo [23] \\
Torpedo tokionis & 86 & 86 & Asahida and Ida [24] \\
\hline
\end{tabular}

$2 n$ : chromosome diploid number; FN: fundamental number; m/sm: metacentric and/or submetacentric chromosome number; $\mathrm{t} / \mathrm{st}$ : telocentric and/or subtelocentric chromosome number.

proved better than $16 \mathrm{~S}$ at resolving higher-order relationships. However, the opposite holds true for the study of lowerorder relationships: $16 \mathrm{~S}$ genes were better at resolving the relationships than the $18 \mathrm{~S}$ genes, and the combined data set was not more informative than $16 \mathrm{~S}$ genes.

The molecular relationships based on $16 \mathrm{~S}$ and $18 \mathrm{~S}$ sequences placed the Torpediniformes distant from the other batoid species in all the phylogenetic trees coming from this analysis. The result was consistent with the earliest hypotheses by Compagno [4, 28, 29] and Maisey [30], but also with a more recent interpretation by McEachran et al. [8] and McEachran and Aschliman [3], who argued that the Torpediniformes are most likely the sister group of the other batoids (Figure 2).

Some studies are currently in progress to implement the information on the evolutionary relationships of other species of electric rays. Research is also being carried out on additional DNA fragments that could be used as molecular markers.

\section{Characterization of Repeated Sequences}

Only in the last few years different molecular approaches, first of all physical mapping on metaphase chromosomes, have been used to investigate the cytotaxonomic relationship among the living cartilaginous fish [27].

Comparative cytogenetics, as a powerful tool to study karyotypic variation, is based on accurate chromosome identification. Physical mapping involves in situ hybridization of specific segments of genomic DNA to their physical location on chromosomes. It is extremely useful in terms of gaining an insight into structural arrangements within the genome. The use of these molecular cytogenetic techniques have often either suggested new taxonomic implications or confirmed the existing phylogenetic relationships among the different fish species analyzed $[27,31,32]$.

Such molecular cytogenetic techniques were particularly helpful in elasmobranch karyology because in these fish genome compartmentalization is not present, as has also been demonstrated in the majority of teleostean species $[33,34]$.

The human telomeric sequence repeats, (TTAGGG) ${ }_{n}$, detected by FISH, were assayed on chromosomes of T. torpedo [35].
FISH allowed the detection of fluorescent signals on the telomeres of both uni- and biarmed elements. An interstitial and/or paracentromeric labeling on four bi-armed chromosomes was also evident (Figure 3). This interstitial FISH pattern might represent further evidence supporting the hypothesis that karyotype evolution in Torpediniformes occurred by a progressive reduction of chromosome number due to centric fusions $[26,36]$. In fact, species that underwent karyotype rearrangements as a result of Robertsonian fusions also show nontelomeric sites of the (TTAGGG) ${ }_{n}$ sequences in addition to the telomeric ones $[37,38]$.

Furthermore, the presence of additional interstitial sites of the (TTAGGG) ${ }_{n}$ sequences in T. torpedo could indicate that, from a karyological point of view, this species is in a phase of active evolutionary change. In fact, the interstitial sites containing (TTAGGG) ${ }_{n}$ sequences are often involved in recombination events [37].

Other remarkable results came from SINE (Short Interspersed Nuclear Elements) sequences analysis in the Torpedo genome.

Retroposons represent a significant portion of repetitive DNA in Eukaryotes. They are mobile genetic elements that are amplified by a reverse transcription of an intermediate RNA [39]. Two large families of retroposons, first identified as interspersed repeated sequences, belong to this genomic component. The LINE (long interspersed nuclear elements) family is made up of long sequences, while the SINE family has short sequences, both irreversibly inserted in the genome [40].

The SINE family was amplified in the elasmobranch genome by PCR [27] using the primers taken from salmonids (HpaI family) [41] and from humans (Alu sequences) [42].

FISH performed with the HpaI-like SINE probe on the T. torpedo chromosome revealed hybridization signals at the centromeric and/or the paracentromeric region on several biarmed chromosomes, while conspicuous fluorescent signals at the centromeric and/or telomeric level on the acrocentric ones were produced (Figure 4(a)), providing a hybridization pattern that is not coincident with that evidenced by C-banding [36]. Such a result is similar to that evidenced by Perez et al. [43] on Atlantic salmon and rainbow trout karyotypes where the members of this SINE family are located only in the euchromatic regions of the chromosomes. 


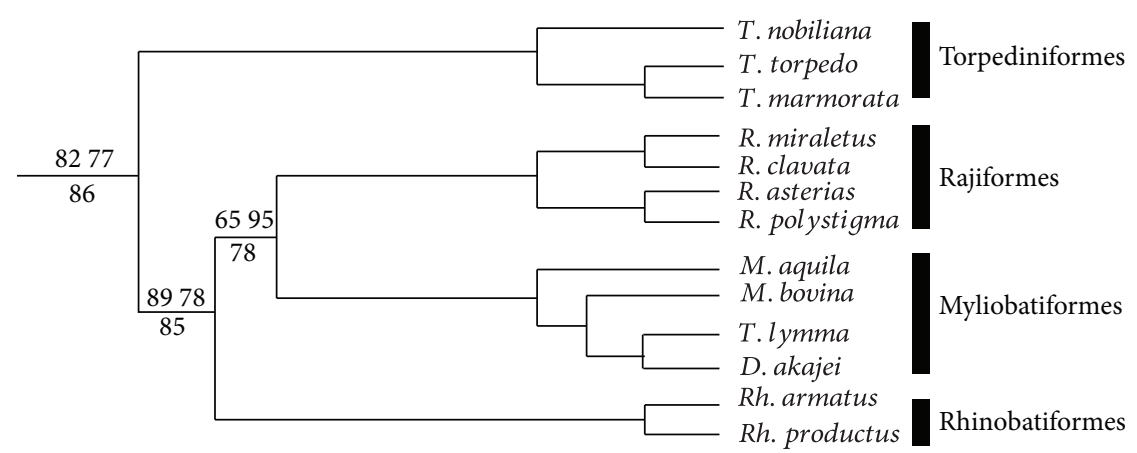

(a)

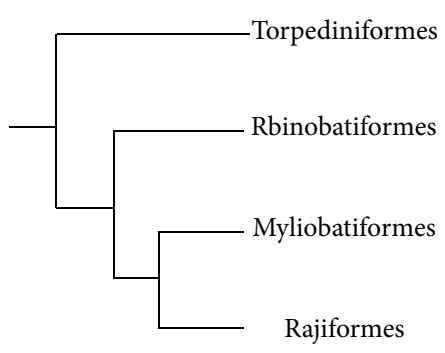

(b)
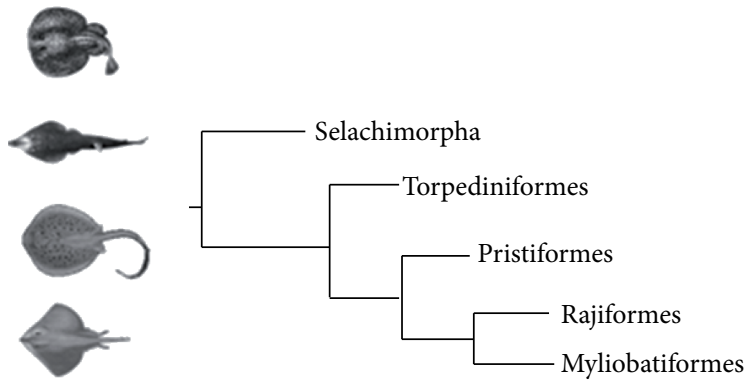

(c)

FIGURE 2: Cladograms illustrating the relationships of extant Batoidea obtained from molecular [14] (a) and morphological data by Compagno [28] (b) and by McEachran and Aschliman, [3] (c). Nodes show bootstrap values for neighbor joining (NJ), maximum parsimony (MP) and posterior probability for Bayesian analyses.

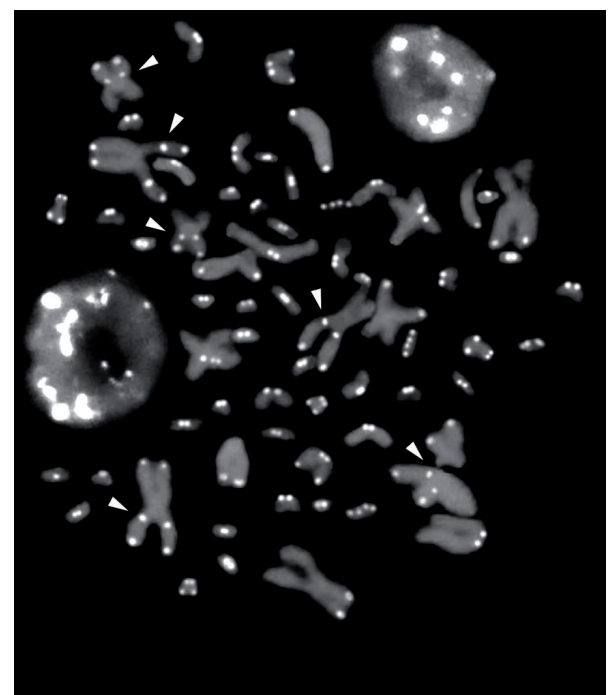

FIGURE 3: In situ hybridization of digoxigenin-labeled (TTAGGG) probe onto T. torpedo metaphase chromosomes. Note the interstitial labeling on bi-armed elements (arrows).

The location of these specific Alu-like sequences on the chromosomes of T. torpedo is prevalently at the centromeric level, as in humans [44], and sometimes at the telomeric level, indicating an intraspecific polymorphisms (Figure 4(b)).

Marçais et al. [45] and Prades et al. [44] observed that the block of alphoid DNA at the centromeres of human chromosomes is susceptible to variations in length created by jumping amplification, with an unequal exchange of large alphoid domains between homologous chromosomes, and deletions of large DNA segments. Probably, through a similar mechanism, these Alu-like sequences retrotransposed within the $T$. torpedo genome to specific sites such as telomeric regions that are particularly exposed to a new insertion of transposable elements [46].

The Hpa I-like SINE and Alu-like sequences from T. torpedo were also hybridized on genomic DNA of four species of Batoidea (Torpedo marmorata, T. torpedo, Raja asterias, and Raja montagui) and two species of Galeomorphii (Mustelus asterias and Scyliorhinus stellaris). The hybridization patterns shown were practically identical in the two rays and in the two Torpedo species (Figures 5 and 6). The results fixed the relationships present among the species attributed to the different superorders examined [29]. In fact, Southern blot analysis revealed a similar hybridization pattern in congeneric species, confirming their close systematic relatedness. The Hpa I-like probe failed to show the hybridization pattern on genomic DNA in Mustelus asterias, probably because the signal of labeling was too weak and under the sensitivity of the technique.

\section{Ribosomal Genes: Nucleotide Sequences and Mapping}

The ribosomal genes are organized into two multigene families in superior eukaryotes. One of these families contains 


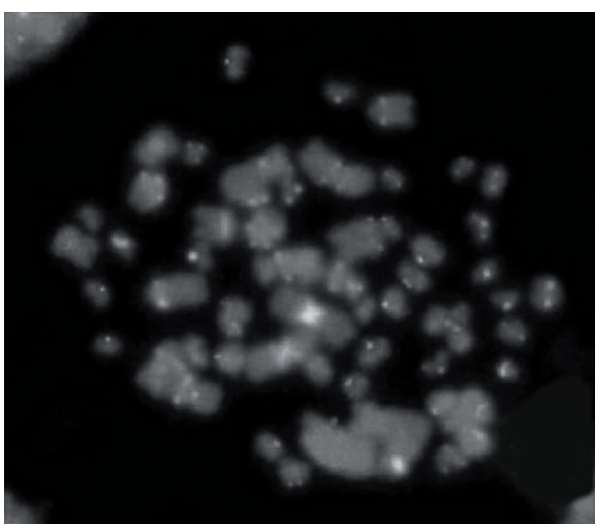

(a)

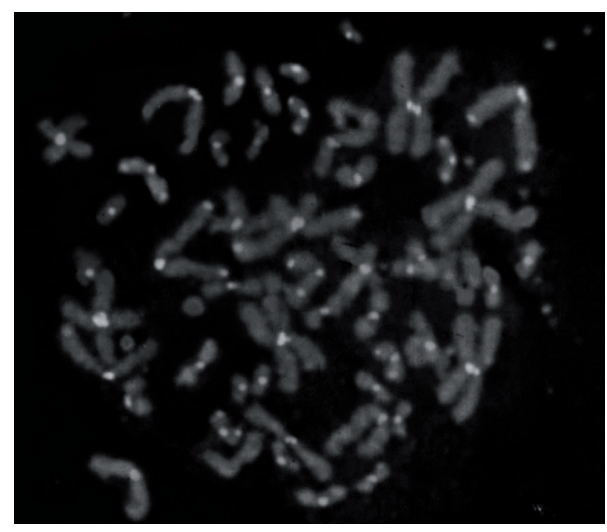

(b)

FIgURE 4: FISH localization of SINE HpaI family (a) and Alu sequences (b) on metaphase chromosomes in T. torpedo.

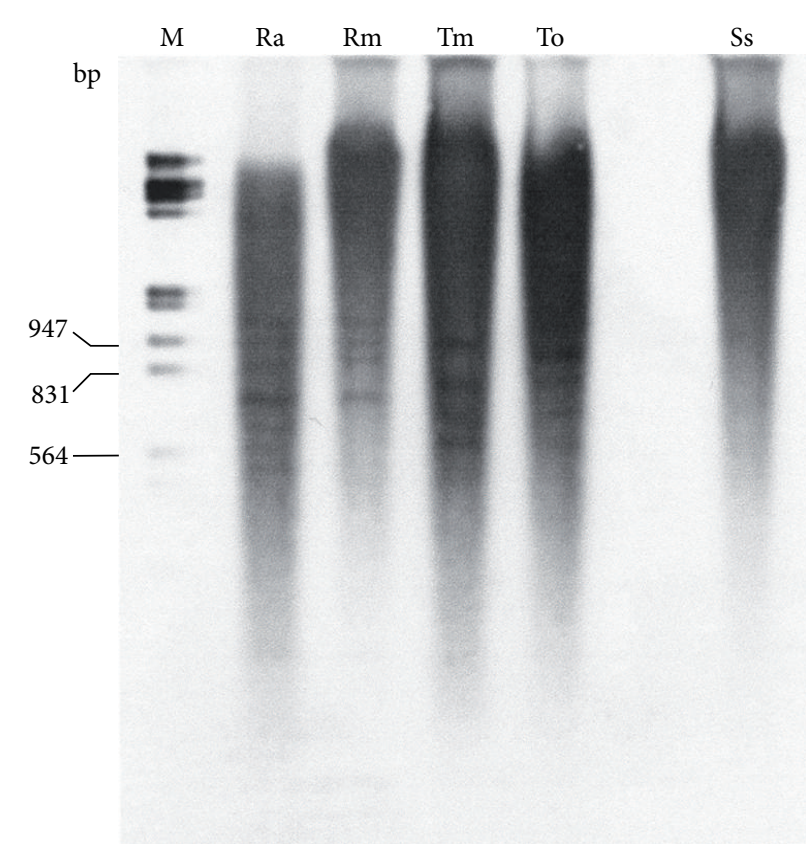

FIGURE 5: Hybridization of SINE HpaI PCR amplification products from T. torpedo on TaqI-digested DNA of some selachian species. M $=\lambda /$ EcoRI-HindIII. To $=$ T. torpedo, $\mathrm{Tm}=$ T. marmorata, $\mathrm{Ra}=$ Raja asterias, $\mathrm{Rm}=R$. montagui, and $\mathrm{Ss}=$ Scyliorhinus stellaris.

the major rDNA (45S) that codes for the 18S, 5.8S, and $28 \mathrm{~S}$ rRNAs, while the other codes for the minor rDNA (5S). The nucleolus organizing regions (NORs) that contain the $45 \mathrm{~S}$ rDNA can be easily identified in chromosomes by silver nitrate (Ag-NORs) or investigated using certain fluorochromes such as Chromomycin A3, especially in fishes, although these fluorochromes only show heterochromatic GC rich regions [47] sometimes interspersed among the ribosomal gene clusters [48].

In Torpediniformes chromosomal localization of major ribosomal genes by using FISH technique has often been associated with fluorochrome and silver-staining techniques.

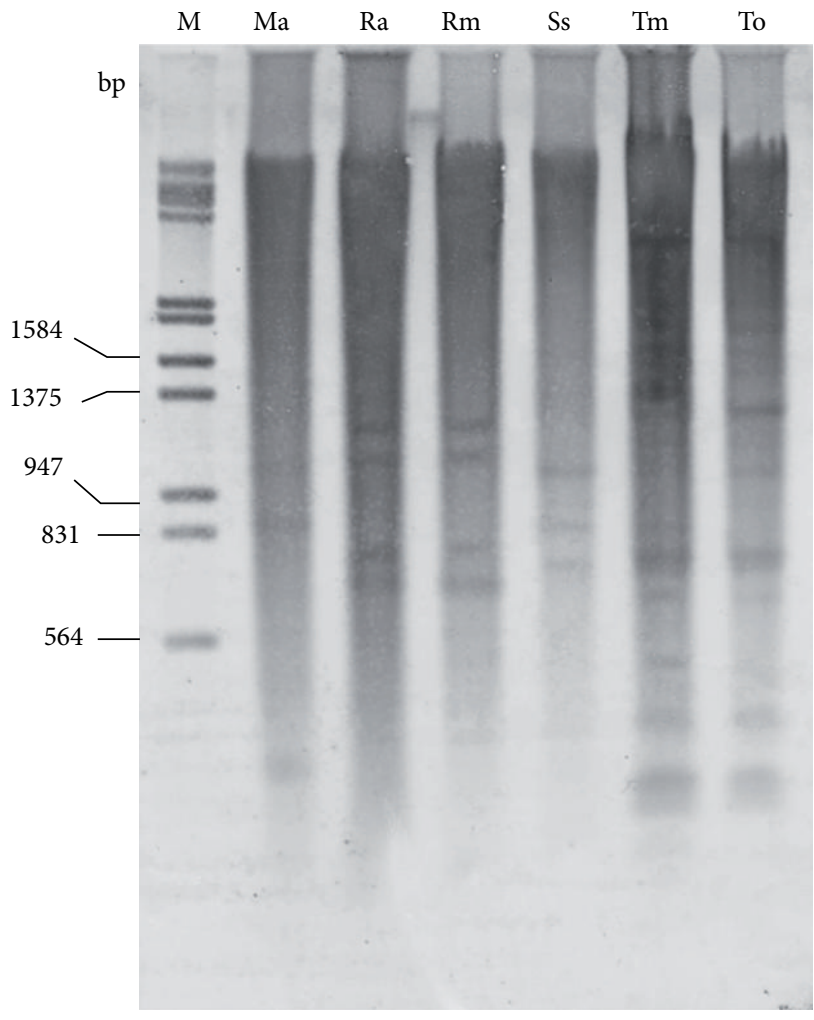

FIgURE 6: Hybridization of Alu PCR amplification products from T. torpedo on EcoRI-digested DNA of some selachian species. $\mathrm{M}=$ $\lambda /$ EcoRI-HindIII; $\mathrm{Ma}=$ Mustelus asterias. For other abbreviations, see Figure 5.

Chromomycin $\mathrm{A}_{3}\left(\mathrm{CMA}_{3}\right)$ is a GC-rich DNA-specific fluorochrome dye and detects the nucleolar organizing regions (NORs) independently of their activity [49] also in cartilaginous fish. Silver (Ag-NOR) staining detects only NORs that are functionally active during the previous interphase [50].

Table 2 reports the number and the chromosome location of $\mathrm{Ag}-\mathrm{NOR}_{s}$ and $\mathrm{CMA}_{3}$ sites as well as those of $18 \mathrm{~S}$ and $5 \mathrm{~S}$ rRNA genes in the Torpedo species so far studied. 


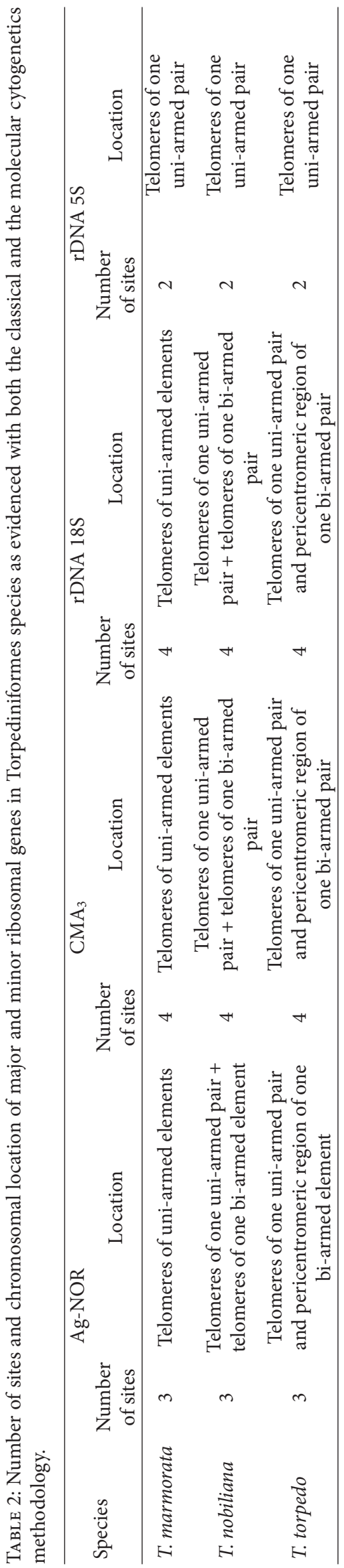


In T. marmorata the silver-nitrate-staining showed AgNOR regions at the telomeric level of two or three acrocentric elements. In T. nobiliana, the Ag-NOR-staining showed two telomeric sites of one pair of acrocentric elements and, in at least $20 \%$ of the plates examined, the Ag-NOR staining was localized at the telomeric level of one small submetacentric chromosome. In T. torpedo, the Ag-NOR staining showed two telomeric sites of one pair of acrocentric elements. Moreover, in at least $20 \%$ of the plates examined, the AgNOR staining was localized at the interstitial level of one submetacentric chromosome.

The rDNA FISH probes were able to reveal all rRNA loci on the chromosomes. The $\mathrm{CMA}_{3}$ staining and FISH technique using $18 \mathrm{~S}$ rDNA showed the fluorescent signals only at the telomeric level of two pairs of chromosomes in T. marmorata. In T. nobiliana signals were found at the telomeric level of one pair of acrocentric elements and one pair of submetacentric elements. In T. torpedo, the markers were at the telomeric level of one pair of acrocentric elements, but with a further banding also at the interstitial level of one pair of major submetacentric elements. Figure 7 shows the schematic representation of the chromosomes involved in the species analyzed. Comparing the results with those evidenced in Rajiformes, it is particularly noteworthy that in the genus Raja multiple sites for NORs were found [51]. The number of chromosome pairs bearing major rDNA is notably decreased in Torpedo.

As far as 5S rDNA organization is concerned, in the three Torpedo species studied, the results of the amplification products by PCR are similar to those reported in literature for other vertebrates. The length of the bands obtained in the different species varies due to the different size and base composition of the nontranscribed spacer (NTS) region. Moreover, the NTS region contains some TATA-like trinucleotides and other short sequences, such as (TGC) $)_{n}$ trinucleotides, (CA) dinucleotides and (GTGA) $)_{n}$ tetranucleotides, which could be involved in the regulation of the gene itself, as has been described for some species of teleosteans [52-54].

The minor ribosomal cluster was, however, localized at the telomeric level of a single pair of acrocentric elements in all three species studied (Figure 7).

The chromosomal localization of 5S rDNA might represent further evidence to support the hypothesis that the karyotype of the Chondrichthyes evolved through fusion of acrocentric elements, forming metacentric or submetacentric ones. The chromosomes bearing the minor ribosomal clusters might, in fact, have been involved in these Robertsonian fusion phenomena that occurred in the karyological evolution of these fish, stemming from a progenitor with more primitive karyotype characteristics such as those of the Raja species.

The study of the organization of ribosomal genes and their chromosomal localization provides a series of informative data, above all when integrated by means of in situ hybridization and sequencing. They, in fact, could provide a better understanding of the molecular bases of the chromosomal structure and function and, more in general, of the arrangements that lead to the processes of speciation.

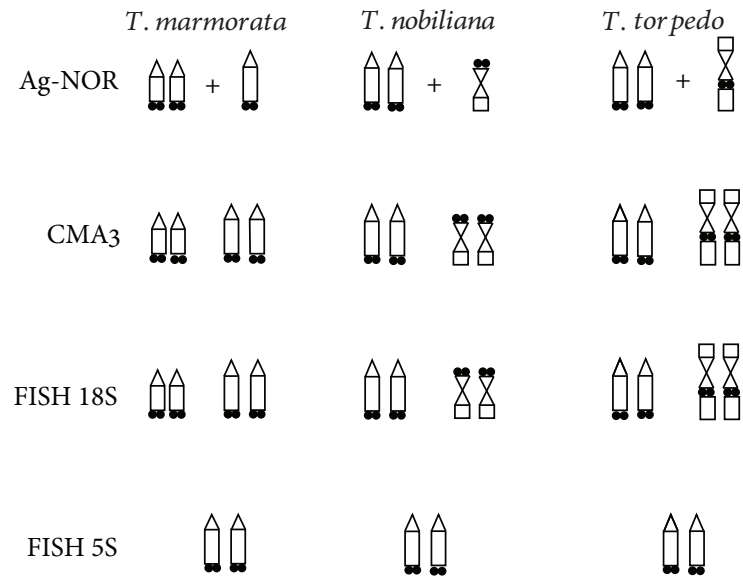

FIgURE 7: Ideograms showing the chromosome pairs bearing the ribosomal clusters (circles) in Torpediniformes species studied so far.

\section{Sex-Related Chromosome Markers}

In cartilaginous fish, sex chromosomes are present in a small number of species (Rhinobatos schlegelii, R. hynnicephalus, and Carcharodon carcharias) $[55,56]$.

In order to identify new molecular chromosomal markers both to discriminate the different chromosome pairs and to distinguish the probable sex chromosomes in the species Torpedo torpedo, another study on some DNA genomic sequences was performed [57].

The research began using specific primers to characterize at the molecular level and to localize on the chromosomes SRY-like sequences; these are the hypothetical regions for sex determination. These are well conserved in mammals, thus allowing the amplification of fragments of entire genes coming from taxonomic groups that are also very heterogeneous. This allowed the amplification of segments of DNA also in this species that had never been studied before in a cartilaginous fish at the molecular genetic level.

As concerns chromosomal localization of the amplification products, the results obtained showed the presence of labels on two pairs of chromosomes in the male, one pair of subtelocentric and one pair of acrocentric elements. In the female, the FISH test showed the presence of labels only on the pair of acrocentric chromosomes. The same result was obtained by hybridizing the male DNA fragments on the female chromosomes and the female DNA probe on the male metaphase plates (Figure 8).

It could seem that the pair of acrocentric elements, which were always marked in both sexes, are homologous, as the patterns of hybridization for these chromosomes and their morphology were the same when FISH was performed with a male or with a female probe. Furthermore, I believe that there is indeed a difference between the genomic composition of the submetacentric elements in the male and in the female, in the light of the nonhybridization on the female chromosomes using the male probe. Further remarkable data came from the sequencing results. The PCR products had similar patterns 


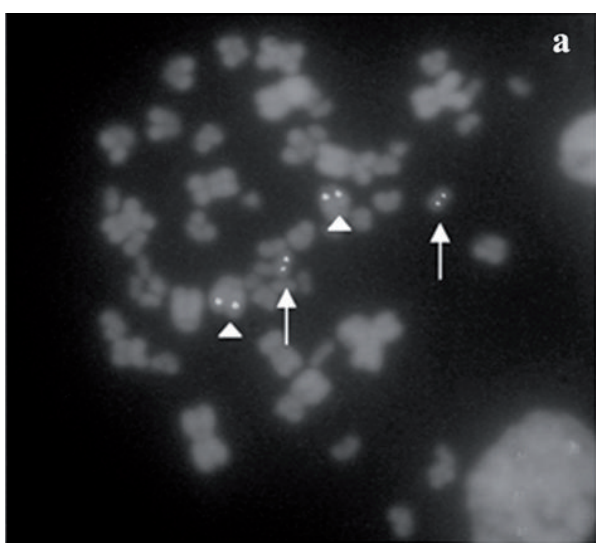

(a)

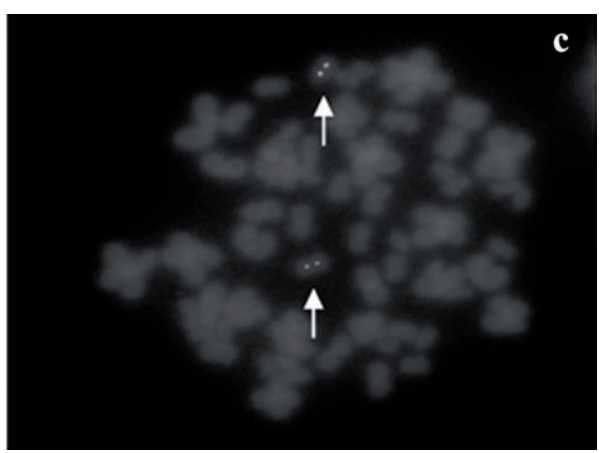

(c)

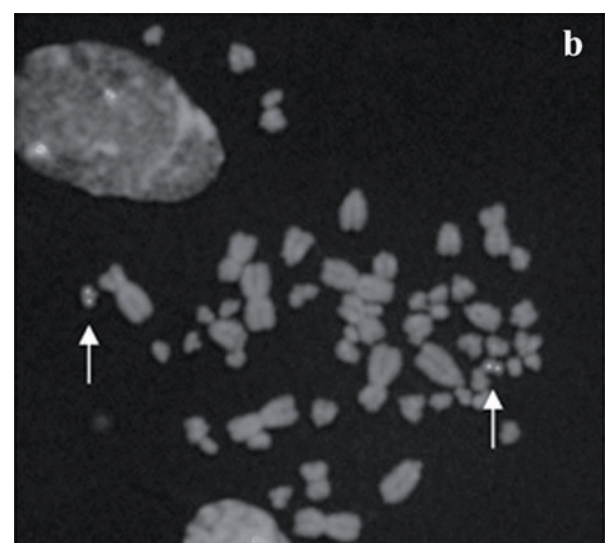

(b)

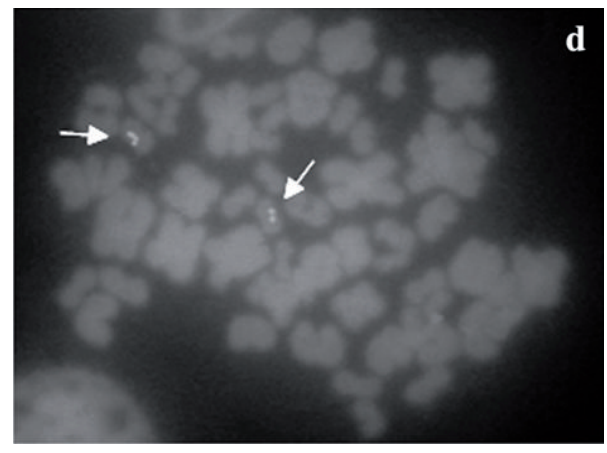

(d)

FIGURE 8: FISH on T. torpedo male chromosomes evidenced the presence of labeling on two pairs, one pair of subtelocentric elements (triangles) and the other of acrocentric ones (arrows) (a). FISH on female metaphase plates showed the presence of spots on one acrocentric chromosome pair (b). FISH with probe taken from male specimens DNA on female chromosomes evidenced the presence of labelings on one acrocentric pair (c). FISH with probe taken from female specimens DNA on male chromosomes evidenced the presence of spots on one acrocentric pair $(\mathrm{d})$.

with two bands of 200 and about $400 \mathrm{bp}$ in length for each sex, that showed, only for the male $400 \mathrm{bp}$ band, an alignment with the human genes SPATA 16, SPATA 18, and UTY.

These genes in man are implicated in the process of spermatogenesis, and presumably also in T. torpedo play a crucial role in sex differentiation. Probably only this $400 \mathrm{bp}$ band of the male is responsible for the difference between the sexes, given that the alignment between the two sequences of $200 \mathrm{bp}$ showed $98 \%$ identity. An explanation could lie in the accumulation of random mutations and rearrangements on the sex-specific chromosomes. In fact, it was hypothesized that sex chromosomes, in fish, reach a differentiated state by means of a genetic mechanism called "Muller's ratchet," by which the accumulation of slightly harmful DNA changes in a population over many generations takes place [58].

\section{Closing Remarks}

The main purpose of this paper was to provide an overview of genetic and cytogenetic molecular markers for the analysis of the cytotaxonomic relationships among Torpediniformes and for the reconstruction of evolutionary interrelationships between this superorder and the other batoid species, using the data published up to now, coming prevalently from my research group. For many years this information has been obtained using the classical cytogenetic methods (C-banding, silver nitrate, and fluorochrome staining) that only allow the description of general chromosome morphology.

The chromosome localization of DNA sequences and genes is important for the analysis of chromosome rearrangements and permits an efficient comparative cytogenetic study among batoid fish species.

Some types of molecular markers that seem to be suited to investigate the different levels of applications in the field of comparative cytogenetics and evolutionary studies have been described. The phylogenetic implications coming from the data should be improved to further clarify the existing relationships.

The evidence presented here confirms the particular genomic organization of Torpediniformes, especially $T$. torpedo, in heteroterms as well as in the superclass of fishes. In this species, large amounts of highly repeated DNA [59], high heterogeneity in the genome composition [26], and a characteristic distribution of heterochromatin, that is never centromeric [36], have all been found. 
Because of the particular marking pattern that was found with several DNA sequences, the meta and submetacentric pairs of T. torpedo are to be considered as chromosome markers and are a valid instrument to reveal particular linkage groups of evolutionary importance.

The ever closer integration between molecular cytogenetic analysis and the deep sequencing using bioinformatic tools will be important to clarify the genomic and chromosome organization in these fascinating species of cartilaginous fish.

\section{Acknowledgments}

The author would like to express her gratitude to Dr. A. Bridgewood for his assistance in revising the English of this manuscript. She would also like to thank Prof. V. Stingo for the critical review of the scientific work and her collaborators, Dr. D. Costagliola, Dr. I. Liguori, and Dr. S. Bencivenga who contributed to some aspects of the research presented in this paper.

\section{References}

[1] N. H. Putnam, T. Butts, D. E. K. Ferrier et al., "The amphioxus genome and the evolution of the chordate karyotype," Nature, vol. 453, no. 7198, pp. 1064-1071, 2008.

[2] J. S. Nelson, Fishes of the World, John Wiley \& Sons, New York, NY, USA, 4th ed edition, 2006.

[3] J. D. McEachran and N. C. Aschliman, "Phylogeny of batoidea," in Biology of Sharks and Their Relatives, J. C. Carrier, J. A. Musick, and M. R. Heithaus, Eds., pp. 79-113, CRC Press, Boca Raton, Fla, USA, 2004.

[4] L. J. V. Compagno, "Interrelationships of living elasmobranchs," in Interrelationships of Fishes, P. H. Greenwood, R. S. Miles, and C. Patterson, Eds., pp. 15-61, Academic Press, New York, NY, USA, 1973.

[5] S. Shirai, "Phylogenetic relationships of angel sharks, with comments on elasmobranch phylogeny (Chondrichthyes: Squatinidae)," Copeia, vol. 2, pp. 505-518, 1992.

[6] S. Shirai, Squalean Phylogeny: A New Framework of "Squaloid" Sharks and Related Taxa, Hokkaido University Press, Sapporo, Japan, 1992.

[7] S. Shirai, "Phylogenetic interrelationships of neoselachians (Chondrichthyes, Euselachii)," in Interrelationships of Fishes, M. L. Stiassny J, L. R. Parenti, and G. D. Johnson, Eds., pp. 9-34, Academic Press, San Diego, Calif, USA, 1996.

[8] J. D. McEachran, K. A. Dunn, and T. Miyake, "Interrelationships of the batoid fishes (Chondrichthyes: Batoidei)," in Interrelationships of Fishes, M. L. Stiassny J, L. R. Parenti, and G. D. Johnson, Eds., pp. 63-84, Academic Press, New York, NY, USA, 1996.

[9] J. D. McEachran and K. A. Dunn, "Phylogenetic analysis of skates, a morphologically conservative Clade of Elasmobranchs (Chondrichthyes: Rajidae)," Copeia, no. 2, pp. 271-290, 1998.

[10] M. N. Dean and P. J. Motta, "Anatomy and functional morphology of the feeding apparatus of the lesser electric ray, Narcine brasiliensis (Elasmobranchii: Batoidea)," Journal of Morphology, vol. 262, no. 1, pp. 462-483, 2004.
[11] M. B. Peach and G. W. Rouse, "Phylogenetic trends in the abundance and distribution of pit organs of elasmobranchs," Acta Zoologica, vol. 85, no. 4, pp. 233-244, 2004.

[12] K. A. Dunn and J. F. Morrisey, "Molecular phylogeny of elasmobranchs," Copeia, vol. 3, pp. 526-531, 1995.

[13] C. J. Douady, M. Dosay, M. S. Shivji, and M. J. Stanhope, "Molecular phylogenetic evidence refuting the hypothesis of Batoidea (rays and skates) as derived sharks," Molecular Phylogenetics and Evolution, vol. 26, no. 2, pp. 215-221, 2003.

[14] L. Rocco, I. Liguori, D. Costagliola, M. A. Morescalchi, F. Tinti, and V. Stingo, "Molecular and karyological aspects of Batoidea (Chondrichthyes, Elasmobranchi) phylogeny," Gene, vol. 389, no. 1, pp. 80-86, 2007.

[15] V. Stingo and L. Rocco, "Selachian cytogenetics: a review," Genetica, vol. 111, no. 1-3, pp. 329-347, 2001.

[16] M. R. De Carvalho, "Higher-level elasmobranch phylogeny, basal squalians, and paraphyly," in Interrelationships of Fishes, M. L. J. Stiassny, L. R. Parenti, and G. D. Johnson, Eds., pp. 35-62, Academic Press, San Diego, Calif, USA, 1996.

[17] R. Lawson, S. J. Burch, S. M. Oughterson, S. Heath, and D. H. Davies, "Evolutionary relationships of cartilaginous fishes: an immunological study," Journal of Zoology, vol. 237, no. 1, pp. 101-106, 1995.

[18] C. J. Winchell, A. P. Martin, and J. Mallatt, "Phylogeny of elasmobranchs based on LSU and SSU ribosomal RNA genes," Molecular Phylogenetics and Evolution, vol. 31, no. 1, pp. 214-224, 2004.

[19] K. A. Dunn, J. D. McEachran, and R. L. Honeycutt, "Molecular phylogenetics of myliobatiform fishes (Chondrichthyes: Myliobatiformes), with comments on the effects of missing data on parsimony and likelihood," Molecular Phylogenetics and Evolution, vol. 27, no. 2, pp. 259-270, 2003.

[20] J. S. Taylor and J. Raes, "Duplication and divergence: the evolution of new genes and old ideas," Annual Review of Genetics, vol. 38, pp. 615-643, 2004.

[21] W. H. Donahue, "A karyotypic study of three species of Rajiformes (Chondrichthyes, pisces)," Canadian Journal of Genetics and Cytology, vol. 16, no. 1, pp. 203-211, 1974.

[22] H. Ida, I. Sato, and N. Miyawaki, "Karyotypes of two species in the order Torpediniformes," Japanese Journal of Ichthyology, vol. 32, pp. 107-111, 1985.

[23] V. Stingo, "Cariologia di due torpedini italiane," Bollettino di Zoologia, vol. 43, pp. 406-407, 1976.

[24] T. Asahida and H. Ida, "Karyotypes of two rays, Torpedo tokionis and Dasyatis matsubarai, and their systematic," Japanese Journal of Ichthyology, vol. 37, pp. 71-75, 1990.

[25] V. Stingo and T. Capriglione, "DNA and chromosomal evolution in cartilaginous fish," in Indo-Pacific Fish Biology, T. Ueno, R. Arai, T. Taniuchi, and K. Matsuura, Eds., pp. 140-147, Ichthyological Society Japan, Tokyo, Japan, 1986.

[26] V. Stingo and L. Rocco, "Chondrichthyan cytogenetics: a comparison with teleosteans," Journal of Molecular Evolution, vol. 33, no. 1, pp. 76-82, 1991.

[27] L. Rocco, "Chromosome markers in cartilaginous fish cytogenetics," in Fish Cytogenetics, E. Pisano, C. Ozouf- Costaz, F. Foresti, and B. G. Kapoor, Eds., pp. 473-490, Science, Enfield, NH, USA, 2007.

[28] L. J. V. Compagno, "Phyletic relationships of living sharks and rays," Integrative and Comparative Biology, vol. 17, no. 2, pp. 303-322, 1977. 
[29] L. J. V. Compagno, "Systematics and body form," in Sharks, Skates and Rays, W. C. Hamlett, Ed., pp. 1-42, Johns Hopkins University Press, Baltimore, Md, USA, 1999.

[30] J. G. Maisey, "Higher elasmobranch phylogeny and biostratigraphy," Zoological Journal of the Linnean Society, vol. 82, no. 1-2, pp. 33-54, 1984.

[31] A. Viñas, M. Abuín, B. G. Pardo, P. Martínez, and L. Sánchez, "Characterization of a new $\mathrm{HpaI}$ centromeric satellite DNA in Salmo salar," Genetica, vol. 121, no. 1, pp. 81-87, 2004.

[32] D. C. Cabral-de-Mello and C. Martins, "Breaking down the genome organization and karyotype differentiation through the epifluorescence microscope lens: insects and fish as models," in Microscopy: Science, Technology, Applications and Education, A. Méndez-Vilas and J. Díaz, Eds., vol. 1 of Formatex Microscopy No. 4, pp. 658-669, Formatex Research Center, Badajoz, Spain, 2010.

[33] L. Medrano, G. Bernardi, J. Couturier, B. Dutrillaux, and G. Bernardi, "Chromosome banding and genome compartmentalization in fishes," Chromosoma, vol. 96, no. 2, pp. 178-183, 1988.

[34] G. Bernardi, "The vertebrate genome: isochores and chromosomal bands," in Chromosomes Today, A. T. Sumner and A. C. Chandle, Eds., vol. 11, pp. 49-60, Chapman and Hall, London, UK, 1993.

[35] L. Rocco, D. Costagliola, and V. Stingo, "(TTAGGG) $)_{n}$ telomeric sequence in selachian chromosomes," Heredity, vol. 87, no. 5, pp. 583-588, 2001.

[36] V. Stingo, L. Rocco, G. Odierna, and M. Bellitti, "NOR and heterochromatin analysis in two cartilaginous fishes by C-, Agand RE (restriction endonuclease)-banding," Cytogenetics and Cell Genetics, vol. 71, no. 3, pp. 228-234, 1995.

[37] J. Meyne, R. J. Baker, H. H. Hobart et al., "Distribution of non-telomeric sites of the (TTAGGG)(n) telomeric sequence in vertebrate chromosomes," Chromosoma, vol. 99, no. 1, pp. 3-10, 1990.

[38] I. Nanda, S. Schneider-Rasp, H. Winking, and M. Schmid, "Loss of telomeric sites in the chromosomes of Mus musculus domesticus (Rodentia: Muridae) during Robertsonian rearrangements," Chromosome Research, vol. 3, no. 7, pp. 399-409, 1995.

[39] J. D. Boeke and S. E. Devine, "Yeast retrotransposons: finding a nice quiet neighborhood," Cell, vol. 93, no. 7, pp. 1087-1089, 1998.

[40] N. Okada, "SINEs: short interspersed repeated elements of the eukaryotic genome," Trends in Ecology and Evolution, vol. 6, no. 11, pp. 358-361, 1991.

[41] Y. Kido, M. Aono, T. Yamaki et al., "Shaping and reshaping of salmonid genomes by amplification of tRNA-derived retroposons during evolution," Proceedings of the National Academy of Sciences of the United States of America, vol. 88, no. 6, pp. 2326-2330, 1991.

[42] Y. Kariya, K. Kato, and Y. Hayashizaki, "Revision of consensus sequence of human Alu repeats-a review," Gene, vol. 53, no. 1, pp. 1-10, 1987.

[43] J. Perez, E. Garcia-Vazquez, and P. Moran, "Physical distribution of SINE elements in the chromosomes of Atlantic salmon and rainbow trout," Heredity, vol. 83, no. 5, pp. 575-579, 1999.

[44] C. Prades, A. M. Laurent, J. Puechberty, Y. Yurov, and G. Roizès, "SINE and LINE within human centromeres," Journal of Molecular Evolution, vol. 42, no. 1, pp. 37-43, 1996.

[45] B. Marcais, J. P. Charlieu, B. Allain, E. Brun, M. Bellis, and G. Roizes, "On the mode of evolution of alpha satellite DNA in human populations," Journal of Molecular Evolution, vol. 33, no. 1, pp. 42-48, 1991.
[46] J. R. Korenberg and M. C. Rykowski, "Human genome organization: alu, lines, and the molecular structure of metaphase chromosome bands," Cell, vol. 53, no. 3, pp. 391-400, 1988.

[47] R. F. Artoni, W. F. Molina, L. A. C. Bertollo, and P. M. Galetti, "Heterochromatin analysis in the fish species Liposarcus anisitsi (Siluriformes) and Leporinus elongatus (Characiformes)," Genetics and Molecular Biology, vol. 22, no. 1, pp. 39-44, 1999.

[48] A. M. Pendas, P. Moran, and E. Garcia-Vazquez, "Ribosomal RNA genes are interspersed throughout a heterochromatic chromosome arm in Atlantic salmon," Cytogenetics and Cell Genetics, vol. 63, no. 2, pp. 128-130, 1993.

[49] M. Schmid and M. Guttenbach, "Evolutionary diversity of reverse (R) fluorescent chromosome bands in vertebrates," Chromosoma, vol. 97, no. 2, pp. 101-114, 1988.

[50] W. M. Howell, "Visualization of ribosomal gene activity: silver proteins associated with rRNA transcribed from oocyte chromosomes," Chromosoma, vol. 62, no. 4, pp. 361-367, 1977.

[51] L. Rocco, D. Costagliola, M. Fiorillo, F. Tinti, and V. Stingo, "Molecular and chromosomal analysis of ribosomal cistrons in two cartilaginous fish, Taeniura lymma and Raja montagui (Chondrichthyes, Batoidea)," Genetica, vol. 123, no. 3, pp. 245-253, 2005.

[52] C. Martins and A. P. Wasko, "Organization and evolution of 5 S ribosomal DNA in the fish genome," in Focus on Genome Research, C. R. Williams, Ed., pp. 335-363, Nova Science, Hauppauge, NY, USA, 2004.

[53] D. Campo, G. MacHado-Schiaffino, J. L. Horreo, and E. GarciaVazquez, "Molecular organization and evolution of 5S rDNA in the genus Merluccius and their phylogenetic implications," Journal of Molecular Evolution, vol. 68, no. 3, pp. 208-216, 2009.

[54] M. Singh, R. Kumar, N. S. Nagpure, B. Kushwaha, I. Gond, and W. S. Lakra, "Chromosomal localization of $18 \mathrm{~s}$ and $5 \mathrm{~s}$ rDNA using FISH in the genus Tor (Pisces, Cyprinidae)," Genetica, vol. 137, no. 3, pp. 245-252, 2009.

[55] T. Asahida and H. Ida, "Karyotype and cellular DNA content of a guitarfish, Rhinobatos schlegelii," La Kromosomo II, vol. 79-80, pp. 2725-2730, 1995.

[56] M. B. Maddock and F. J. Schwartz, "Elasmobranch cytogenetics: methods and sex chromosomes," Bulletin of Marine Science, vol. 58, no. 1, pp. 147-155, 1996.

[57] L. Rocco, S. Bencivenga, A. Archimandritis, and V. Stingo, "Molecular characterization and chromosomal localization of spermatogenesis related sequences in Torpedo torpedo (Chondrichthyes, Torpediniformes)," Marine Genomics, vol. 2, no. 2, pp. 99-102, 2009.

[58] L. Loewe and D. K. Lamatsch, "Quantifying the threat of extinction from Muller's ratchet in the diploid Amazon molly (Poecilia formosa)," BMC Evolutionary Biology, vol. 8, no. 1, article 88, 2008.

[59] E. Olmo, V. Stingo, O. Cobror, T. Capriglione, and G. Odierna, "Repetitive DNA and polyploidy in selachians," Comparative Biochemistry and Physiology-Part B, vol. 73, no. 4, pp. 739-745, 1982. 

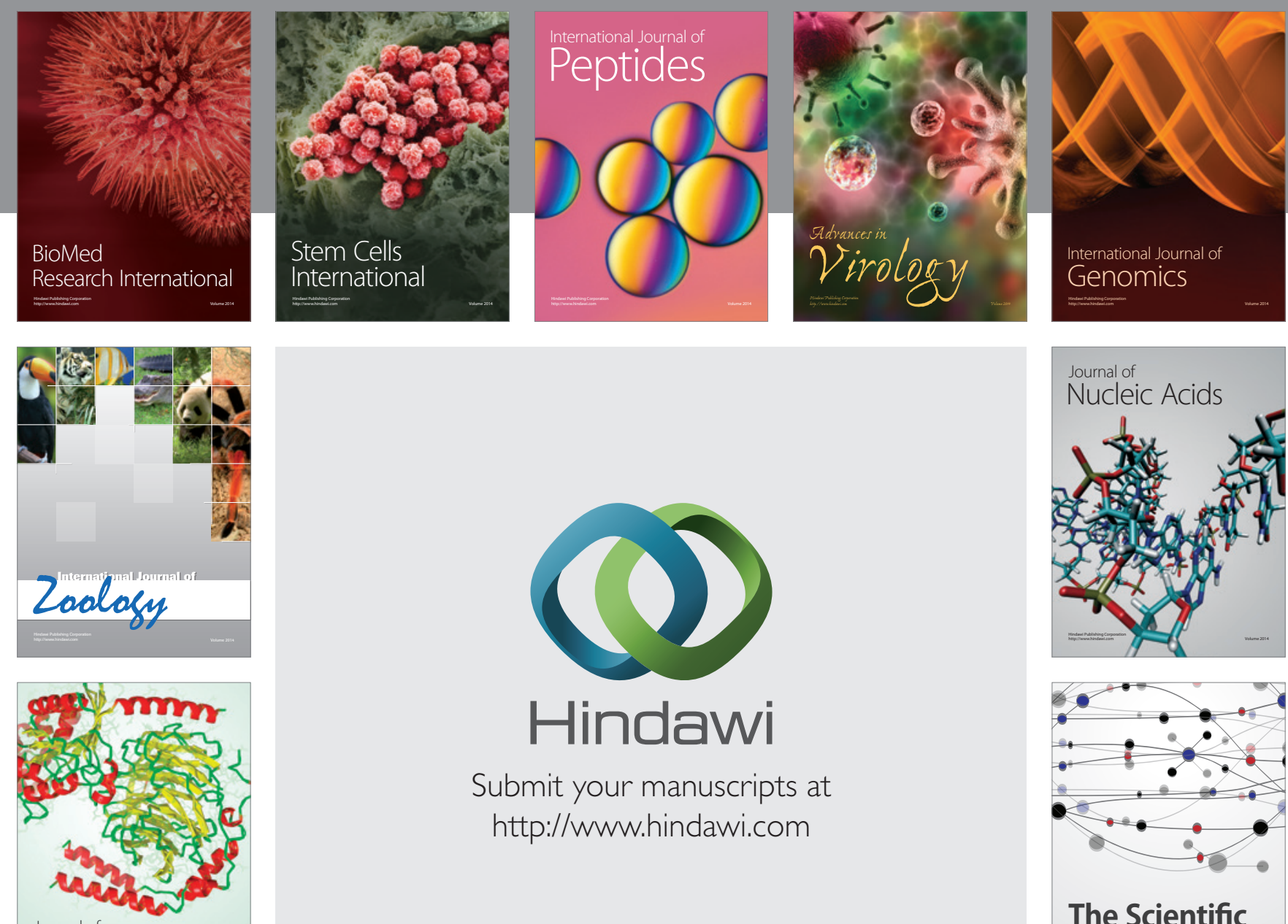

Submit your manuscripts at

http://www.hindawi.com

Journal of
Signal Transduction
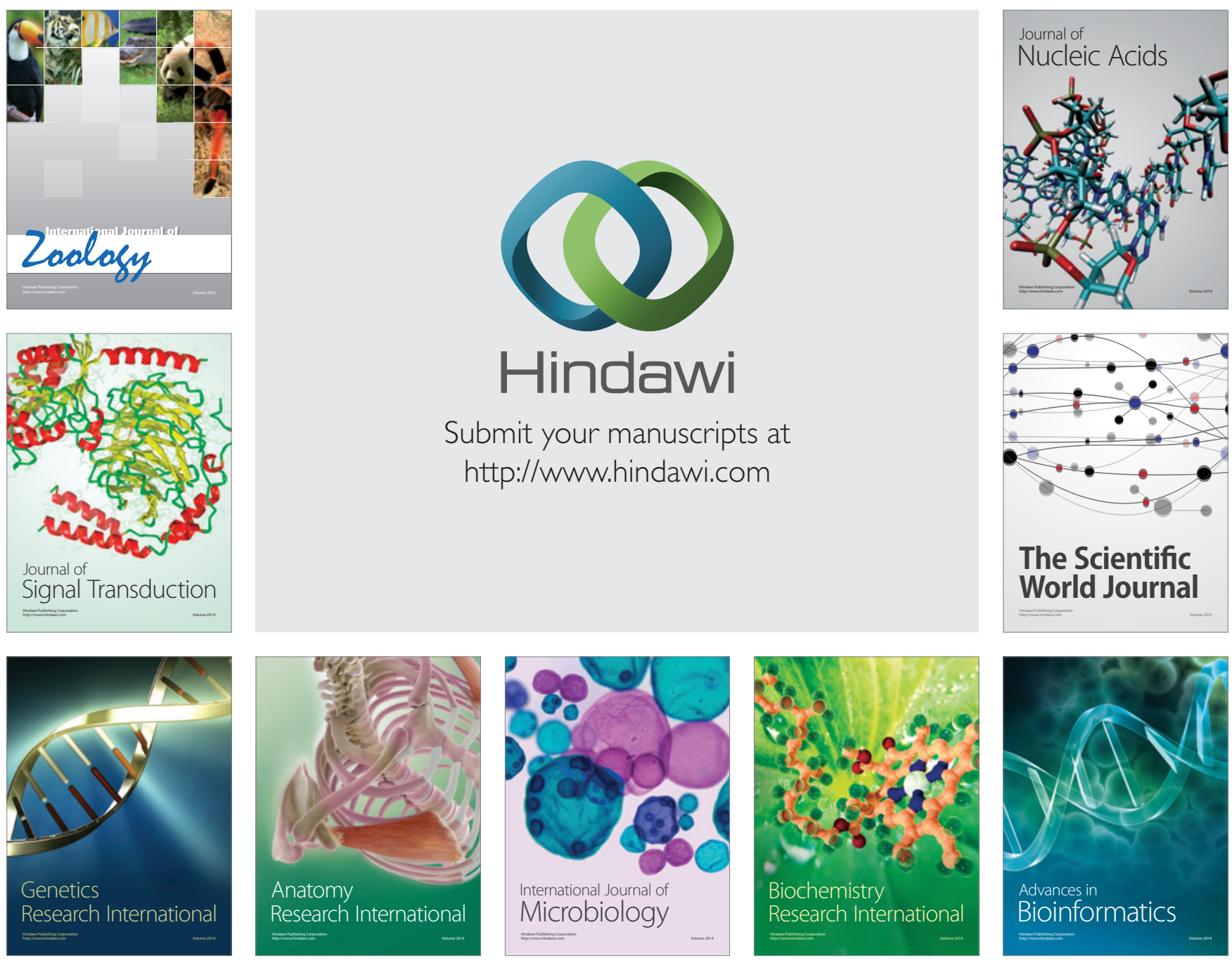

The Scientific World Journal
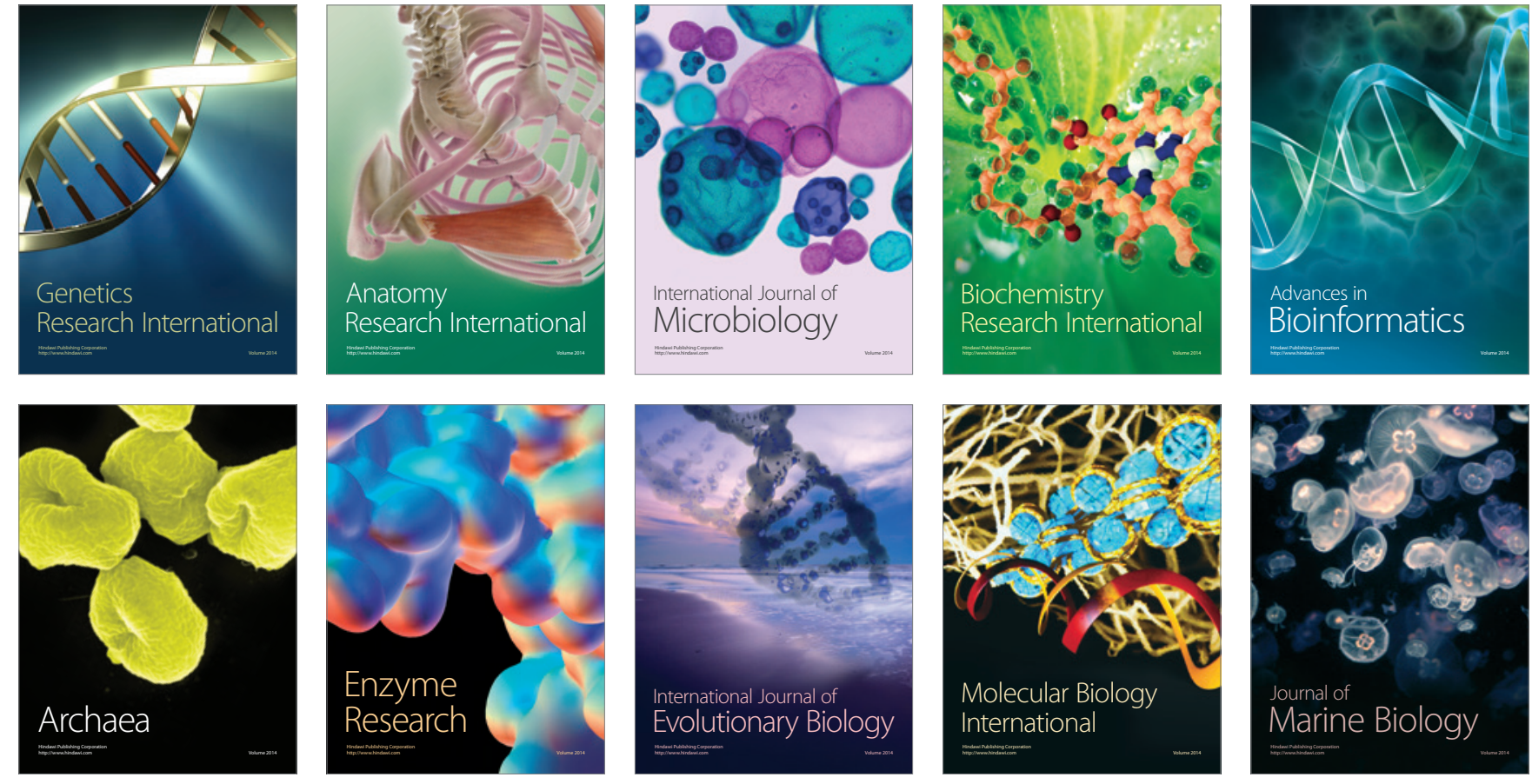